\title{
GLOBAL CITIZENS AND WORLD HERITAGE: SOCIAL INCLUSION OF ONLINE COMMUNITIES IN HERITAGE PLANNING
}

\author{
Nan Bai $^{1}$, Pirouz Nourian ${ }^{2}$, Ana Pereira Roders ${ }^{1}$ \\ ${ }^{1}$ UNESCO chair in Heritage and the Reshaping of Urban Conservation for Sustainability, \\ Chair of Heritage and Values, Delft University of Technology, Delft, the Netherlands - (n.bai, a.r.pereira-roders)@tudelft.nl \\ ${ }^{2}$ Chair of Design Informatics, Delft University of Technology, Delft, the Netherlands - p.nourian@tudelft.nl
}

KEY WORDS: Heritage Planning, Social Inclusion, Social Media, Public Awareness, Systematic Literature Review

\begin{abstract}
:
Social inclusion has grown as an important goal for heritage planning over the past decades. Whilst the document Recommendation on the Historic Urban Landscape called a decade ago for novel tools for civic engagement and knowledge documentation, social media already functions as a platform for online communities to actively get involved in heritage-related activities by sharing their ideas. Especially when radical events occur around heritage properties, either positive or negative, emotions and opinions would spread rapidly across the globe via the internet to reach online communities of interested or concerned citizens. This paper presents a theoretical framework defined to classify social inclusion of online communities in heritage planning processes through differentiating the everyday baseline scenarios from the event-triggered activated ones. A preliminary systematic literature review shows that research integrating and comparing both scenarios is still scarce, and that specific tools and algorithms to handle large datasets are needed to identify the structure of communication networks underpinning the spread of information on social media. This framework is the first step on future research to investigate the different focal attention points, mechanisms, and patterns of social inclusion of online communities in heritage planning, towards transforming it to a more socially inclusive practice.
\end{abstract}

\section{INTRODUCTION}

Social inclusion and public participation have been extensively discussed in heritage planning in the last decades, both in research and practice. Heritage is diverse in category (natural and cultural, tangible and intangible, etc.), and also in nomination level, ranging from international lists such as UNESCO World Heritage List, to national, regional, and local levels, often overlapping in attributes and values with cultural significance. Aside from the official listing, heritage often has overlaying meanings and cultural significance conveyed by local citizens, tourists, and experts (Pereira Roders, 2019; Waterton et al., 2006; Australia ICOMOS, 2013). However, the aim of social inclusion is harder to achieve when only societal representatives (public sectors and experts) decide on heritage planning. According to Taylor and Gibson (2017), simply providing digitized heritage to stakeholders will not increase the perception of social inclusion. As defined by social psychologists, Social Inclusion is "the degree to which an individual perceives that the group provides him or her with a sense of belonging and authenticity", with belonging and authenticity as two major dimensions (Jansen et al., 2014). This also applies in heritage planning. The Recommendation on the Historic Urban Landscape (HUL) adopted by UNESCO in 2011 promotes the participation of a broader variety of stakeholders in heritage planning, including actors from local to international, private to public, and experts to communities. The Recommendation also calls for developing tools that enable public participation and knowledge documentation, whereas social media is foreseen to strongly contribute to better social inclusion (Bandarin and Van Oers, 2012; UNESCO, 2011). With the help of social media, everyone can join the heritage planning processes by expressing their opinions and emotions publicly and instantly, even if not involved in decision-making processes. Social media provides the chance to rationally increase and develop pub- lic's input as systematic knowledge into the heritage planning processes (Olsson, 2008).

Right after the fire in Notre-Dame de Paris on the 15th of April, 2019, sorrow and shock spread over social media worldwide, growing rapidly in platforms like Facebook, Twitter, Instagram, WeChat, and TripAdvisor. Many posts also pointed out which sector was to blame, and discussed whether or not should NotreDame be repaired, restored, or redesigned. This conversation has continued all the way to the recent days - two years after the fire and one year since the Covid-19 pandemic started to spread and paused the normal social life. The main emotion to be found on social media comes back to normal states, and people start to integrate Notre-Dame again in their posts sharing their daily lives, expressing how "lovely" Notre-Dame still is though it is still "healing" and "ongoing to rebuild". In some similar cases like the fire in Notre-Dame, when radical events happened, the communities worldwide would use social media platforms as a tool for actively getting involved, and therefore included in the heritage planning processes. They temporally formulate a group of concerned global citizens and [re]act actively. Their emotions, opinions, and reactions, are also calling the attention of heritage managers and experts to make more responsible planning decisions. Emotions and opinions can be spread through social media in a viral way when such drastic events happen, sometimes even forming a secondary crisis for the heritage managers (Lipizzi et al., 2015; Schroeder et al., 2013; Zhai et al., 2020; Adamic et al., 2016; Bruns et al., 2012).

In the meantime, social media also function as platforms for expressing collective ideas on people-centred heritage in an everyday scenario (Ginzarly et al., 2019). By sharing pictures, making comments, leaving tags, and giving rates to places listed as heritage, people are deliberately or unintentionally passing the

1 The terms are induced from Flickr, Instagram and TripAdvisor posts. 


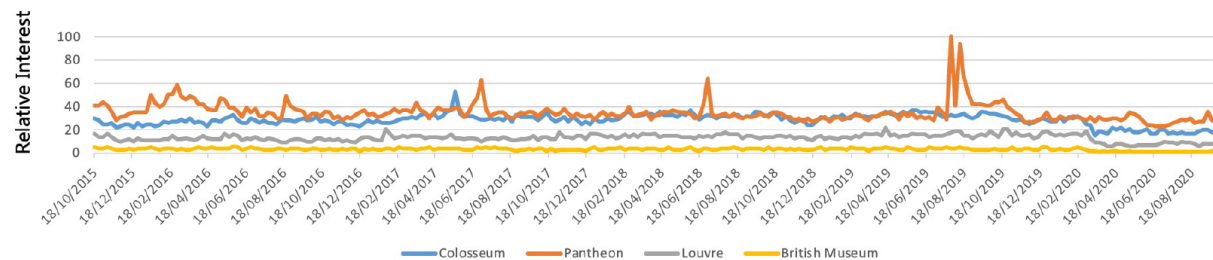

ORDINARY EVERYDAY

BASELINE

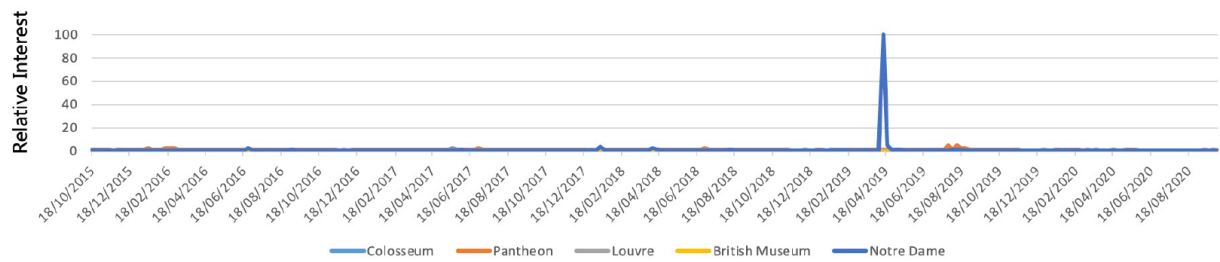

ACTIVATED

EVENT-TRIGGERED

Figure 1. The relative search interest of five heritage properties between 2015 to 2020 on Google Trend search engine. Adding Notre-Dame diminishes the evenly distributed relative search interests. These graphs illustrate both the everyday baseline scenarios

(evenly-distributed dates along the two graphs) and activated event-triggered scenarios (the occasional peaks in both graphs).

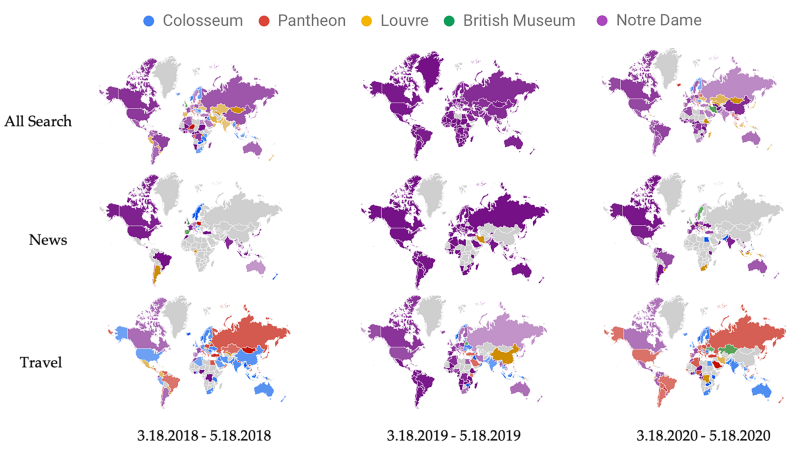

Figure 2. The heatmaps showing relative search interest for countries and regions globally of five heritage properties within two months (March 18 to May 18) in 2018-2020 on Google Trend search engine under the search categories of "All Search", "News", and "Travel", respectively.

understanding and perception of the values the places convey to them. By actively expressing the immediate observations on heritage, stakeholders including locals and tourists are involved to co-create the heritage experiences, which in turn could inform heritage planning (Munar, 2012; van Dijck, 2011), thus becoming positive "prosumers" in a much more democratic designing procedure (Fischer, 2009).

Borrowing concepts from neuroscience, the aforementioned two different scenarios can be interpreted as baseline (everyday) scenarios and activated (event-triggered) ones, as occurred to Notre-Dame. Both scenarios are crucial in understanding the social inclusion processes and their potential influence on heritage planning (Roders and Van Oers, 2011). Figure 1 shows the evenly-distributed relative search interests of four major heritage properties between 2015-2020, comparing to the activated scenario caused by the fire in Notre-Dame de Paris on Google Trend search engine ${ }^{2}$. The vertical axes show the relative search interest while the most searched term during the shown period would be counted as 100, and the other points would be scaled accordingly. The extreme focus on NotreDame de Paris in April 2019 when the fire happened diminished

\footnotetext{
${ }^{2}$ https://trends.google.com/trends
}

all the other interests on a relative scale. A further example of the online communities concerning with Notre-Dame globally can also be seen in Figure 2. When looking at the dominant searching keyword among the five cultural heritage properties (same as in Figure 1), it could be observed that one year before and one year after the fire, the global search interests have been more diverse. And during the outburst of the fire, almost the whole globe focused on Notre-Dame, clearly showing that the world got more densely connected and "smaller" in the activated scenarios (Milgram, 1967; Watts and Strogatz, 1998), which can transcend the geographical and cultural boundaries.

This paper presents and discusses a theoretical framework of an ongoing research to differentiate the online communities' social inclusion in heritage planning as everyday baseline scenarios with the event-triggered activated ones. It shows preliminary results of a systematic literature review concerning the use of social media User-Generated Contents (UGC) in heritage planning, where the classification of both scenarios is contextualized and validated.

\section{FRAMEWORK AND SOCIAL RELEVANCE}

As a more specific definition, this paper refers to "activated" scenario when radical events happen concerning with a heritage property, causing a peak in online discussion and search interest for a short period, while the "baseline" scenario refers to all other ordinary time. This distinction is shown in Figure 1 with the case of the large peak caused by fire in Notre-Dame and the several small peaks with Pantheon. Google Trends Engine could detect such "breakout" events as "rising searches" based on their algorithms ${ }^{3}$. However, such detection would not automatically promise that the outbursts would exactly match and relate to the heritage properties. Additional checks have to be paired as specific interpretation for such detected events. For example, the breakout of searches on "Pantheon" in August 2019 was due to the rework of a character with the same name in the video game "League of Legends", which is weakly relevant to the former Roman temple, though not totally unrelated. Furthermore, the radical events raising public attention are not necessarily negative. A similar search as Figure 1 conducted

\footnotetext{
3 https://support.google.com/trends/answer/4355000
} 
with five cities during April 2019 to April 2020 is demonstrated in Figure 3. The two peaks in Venice were respectively about the exceptional flood in November 2019 and the appearance of dolphins in the canals in March 2020.

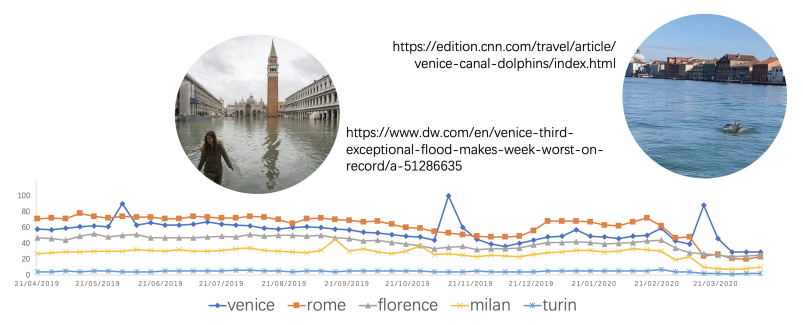

Figure 3. The relative search interest of five cities in part listed as World Heritage between April 2019 to 2020 on Google Trend search engine. The two main events happened in Venice causing discussion peaks are paired with corresponding news articles.

The both scenarios could be relevant to heritage management and spatial planning (Janssen et al., 2017). According to Couclelis (2005), the function of planning can be operational, managerial, and strategic, corresponding to different time orientations of the past, present, and future, respectively. Planning actions in heritage context could have different meanings. For baseline scenario, the planning actions can inform the official narratives towards the heritage attributes and values, which are usually decisions by both the local heritage managers and global organizations (e.g., UNESCO, ICOMOS, and IUCN) on what has to be preserved, what can be changed, and what must be erased (strategic planning including actions to adapt, prepare, shape et al.). For activated scenario, the planning actions can refer to the official reactions towards the events and their further strategies (operational and managerial planning including actions to react, respond, mitigate and manage). Both planning approaches correspond with the main steps in HUL, i.e., "step 2 to help determine what to protect for the future" and "step 4 to integrate the cultural heritage in city development" for baseline scenario, as well as "step 5 to prioritize actions for conservation and development" and "step 6 to develop mechanisms for coordination of the various activities between different actors" for activated scenario (Pereira Roders, 2019). Considering the relationship between the online public and the authorised heritage discourse in both scenarios, social inclusion could be confirmed and further enhanced.

As for the baseline scenario, this relationship means how well the attributes identified by the experts conveying values are reflected in daily life for ordinary people. For most listed UNESCO World Heritage properties, there is a thorough statement defining its Outstanding Universal Value (OUV), pointing out the unique and exceptional attributes associated with certain values, satisfying one or many of the ten Criteria for Selection (UNESCO, 1972, 2008; IUCN et al., 2010). The OUV shows different aspects of exceptional values of the listed properties, which fall into the category of social, economic, political, historic, aesthetic, scientific, age, and ecological values, showing their cultural significance (Tarrafa Silva and Pereira Roders, 2010). However, for local people or tourists visiting the property, it is not expected that any of them would read the inscription documents and know about the OUV listed. By comparing the official discourse and the expressions on social media, heritage experts can investigate what are the values explicitly understood and perceived by the locals and visitors, which can improve future policy-making (van Dijck, 2011; Ginzarly et al., 2019). Both the values and attributes referenced in Statements of OUV but not broadly expressed by the public, and the ones that are popular in the public yet not listed in global, national, regional, and/or local official documents with cultural significance, are crucial information for heritage planning in the constant process of cultural changes (Pereira Roders, 2019; Rochon, 1998). This relationship can also become a reference for future inscribing and delisting decisions of World Heritage property nominations, by taking more information from the public. In such a way, the selection, maintenance, and management of the heritage can become a dynamic evolution process, which could be more responsible and rational for the whole society as well as future generations (Jokilehto, 2006, 2008).

On the other hand, as for the activated scenario, this relationship mainly concerns how decision makers and heritage managers deal with radical events properly considering the collective reaction from online communities. At the beginning phase of the epidemic spreading of event-related information, the collective emotions (usually anger, sorrow, and happiness if the event is positive) infect through the network rapidly by contagious contacts and are easily out of control (Zhai et al., 2020). It is rather strategical for operators and managers to choose a proper moment, a proper way, and some proper sources to broadcast the official reaction (Easley and Kleinberg, 2010; Dong et al., 2012; Pentland, 2015; Aggarwal, 2011). How instant the reactions are, and to how much extend the public concerning is reflected on the reactions, can strongly influence the reliability and credibility of the heritage managers in the local, regional, and even global communities. For the later decisionmaking phase concerning a new policy with the same issue, if no concerns from the previous discussions by the online communities are properly reflected and reacted, the activation of public opinions can be called up again (Cheng et al., 2016). All such reactions and emotions associated with events could also be reported in documents such as Periodical Reporting, State of Conservation reporting, and Reactive Monitoring about threats, common to World Heritage properties.

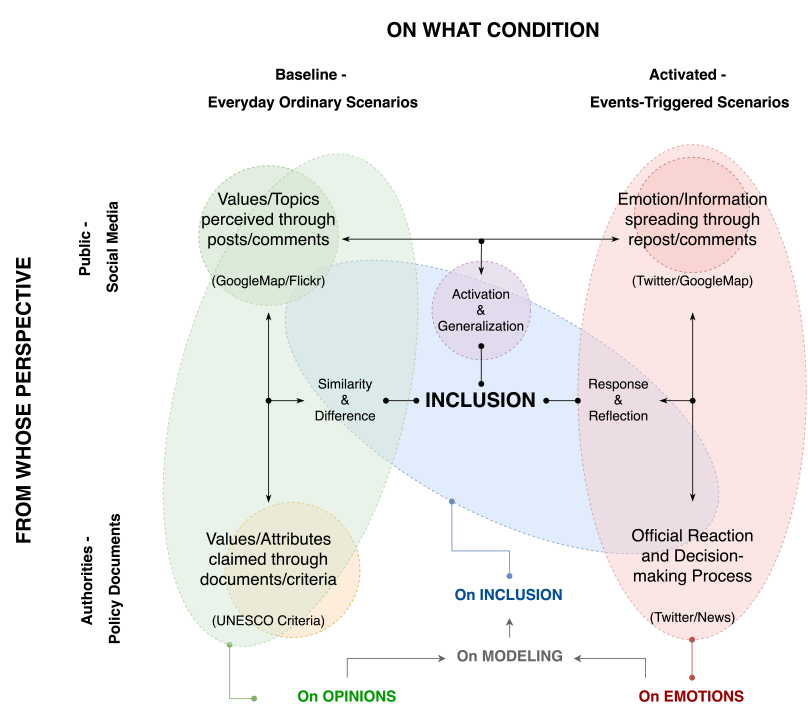

Figure 4. The proposed research framework diagram considering the both scenarios of baseline and activation and the both perspectives of authorities and public.

As such, a research framework has been proposed to investig- 
ate the complex relationship of both authority-public discourses and baseline-activated scenarios, as shown in Figure 4. The aim of this research is to model, analyse, and explain the characteristics and the mechanisms of emergent social inclusion in the social media platforms about heritage properties, and to propose a set of analytical tools to improve social inclusion in future heritage management process. Four main topics will be considered, respectively on the opinions about heritage values and attributes, emotions about radical events, mathematical modeling of the social media networks, and inclusion in planning process. The research questions that the framework is designed to answer are specified as:

1. As for a baseline scenario, how to model and map the OPINIONS networks about heritage values and attributes? How does the public opinions differ from the ones referencing to their Outstanding Universal Value?

2. As for an activated scenario, how to model the mechanism of the EMOTION/information spreading on social media platforms when some radical events happen about a heritage property, and how does it influence the official decision-making process?

3. How can a mathematical model of an emergent social network of concerned citizens be made to replicate its dynamics in both scenarios?

4. How can the evidence-based research findings generalize and improve the power and degree of social INCLUSION in future heritage management in broader cases?

The first three questions can be specified further in terms of identifying the [generalized] structure of communication networks on social media from given signal responses in baseline and activated scenarios (Adams and MacKay, 2007). In other words, it would be preferred to find an abstract network model as a graph that could function the same way as the real communication network consisted of many individuals on social media, whose nodes would represent the cliquish communities of global citizens who care enough about the heritage to a degree that they would express their opinions and emotions on social media platforms (Pentland, 2015; Wasserman and Faust, 1994; Katz, 1953; Lazer et al., 2009). Moreover, the results of the future studies in this direction will have the potential to be extended to other domains of application such as Participatory Value Evaluation to inform policy makers on policy choices through Civic Engagement, which will be addressed in the third question (Calder et al., 2018; Bond and Messing, 2015).

In the following Section 3, partial results from a preliminary systematic literature review are presented, focusing on the current status of both scenarios in heritage planning literature.

\section{SYSTEMATIC LITERATURE REVIEW}

\subsection{Review Process}

Following the principles suggested by Boland et al. (2017), keyword searches were performed on SCOPUS and Web of Science on 24th and 25th March, 2020, respectively. The searches included the title, abstract and keywords of journal articles, conference papers, and book chapters. The search string was finalized as "(Heritage OR UNESCO OR Touris* OR HUL OR 'Historic Urban Landscape') AND ('social media') AND
\{( 'Machine Learning' OR 'Deep Learning' OR 'Information Retriev*' OR 'Text Mining') OR ('Graph Theory' OR 'Social Network' OR 'Complex Network' OR 'Network Science') OR [(Negotia* OR Inclusi* OR Democra* OR Democra*) AND (Planning OR Management)]\}". The search intended to extract publications related to the use of social media in heritage studies with specific methodological focuses on machine learning, network analyses, and/or inclusive planning, as they were most relevant to the proposed research framework shown in Figure 4. As a note, the terms concerning both scenarios "baseline/everyday" and "activated/event-triggered" were not used explicitly in the search, since it is not desirable to refine the results to only focus on the scenarios. Ideally, the both scenarios would be automatically included in the extracted publications since the classification framework is assumed to cover most heritage-related empirical studies using social media data. Initially 327 publications were extracted from SCOPUS and 238 from Web of Science, making up a total of 431 publications for screening and reading after merging and removing the redundant ones.

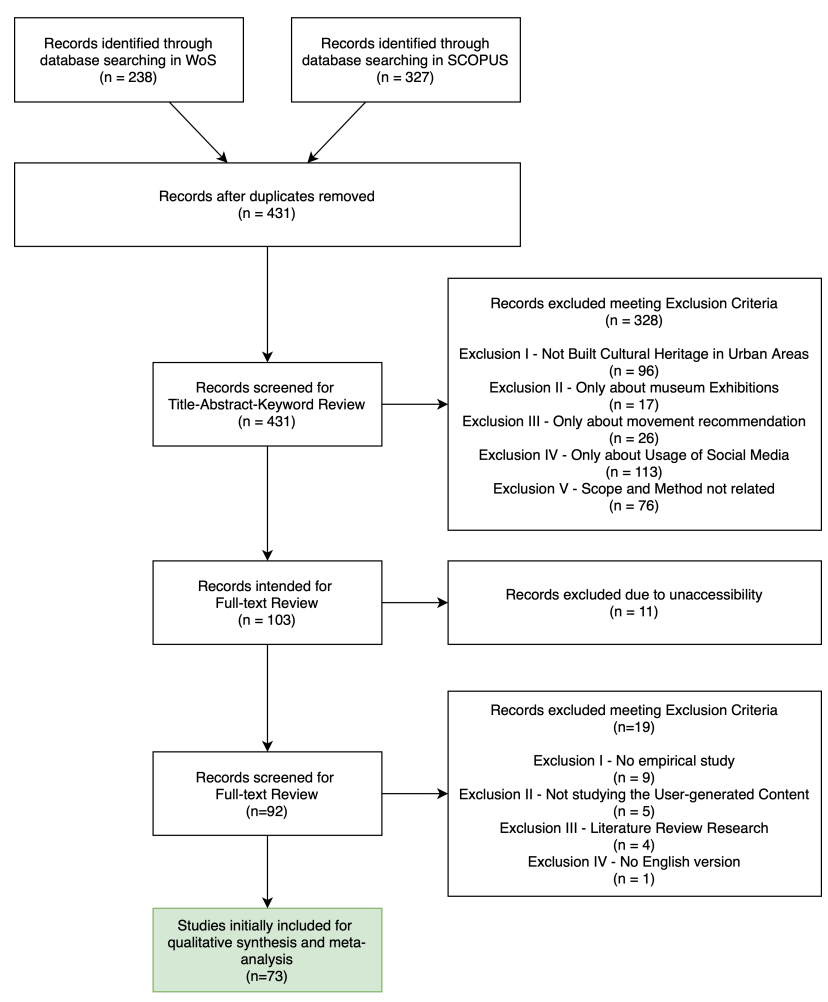

Figure 5. The systematic literature review protocol.

Two sets of inclusion/exclusion criteria were applied respectively for the two stages of title/abstract screening and full-text reading to filter out the articles weakly related to the proposed framework. For the first stage, publications that only focused on hospitality industry (96), museum exhibition (17), destination recommendation system (26), social media marketing strategy (113), computation algorithms (76), and that were openly inaccessible (11) were excluded, yielding 92 publications for the second stage of full-text reading. Nineteen publications were further excluded from the qualitative synthesis since they did not include empirical studies (9), not related to any aspect of User-Generated Content on social media (5), were literature review paper (4), or did not have English version available (1). As a result, 73 publications were included and analysed with quantitative description, qualitative synthesis and statist- 


\begin{tabular}{|c|c|c|c|c|c|c|c|c|c|c|}
\hline Study & Scenario & Data Source & Case Study & Event & Polarity & Collection Duration & $\begin{array}{l}\text { Data } \\
\text { Size }\end{array}$ & Data Type & $\begin{array}{l}\text { Heritage } \\
\text { Type }\end{array}$ & $\begin{array}{l}\text { Case } \\
\text { Count }\end{array}$ \\
\hline Amato et al. (2016) & Activated & Twitter & Naples, Italy* & $\begin{array}{l}\text { Assumptive guided tour for } \\
\text { masterpieces of Caravaggio }\end{array}$ & Positive & - & - & Content \& Context & Cultural & Single \\
\hline $\begin{array}{l}\text { Barbagallo et al. } \\
(2012)\end{array}$ & Both & Twitter & Milan, Italy* & $\begin{array}{l}\text { General negative comments in } \\
\text { tourism and culture domain }\end{array}$ & Negative & Jan - Apr 2011 & $676 \mathrm{k}$ & Structure & Cultural & Single \\
\hline Battiato et al. (2016) & Both & The Social Picture & Pisa, Italy* & Cultural-related public events & Positive & - & $3 \mathrm{k}$ & Content \& Context & Cultural & Single \\
\hline $\begin{array}{l}\text { Campillo-Alhama and } \\
\text { Martinez-Sala (2019) }\end{array}$ & Activated & Facebook \& Twitter & 40 Spanish properties* & $\begin{array}{l}\text { Heritage-property-related } \\
\text { public events }\end{array}$ & Positive & Jan - Dec 2017 & 570 & Structure \& Context & Cultural & Multiple \\
\hline Chaabani et al. (2018) & tivated & Twitter & Tunis, Tunisia* & Arab Spring Revolution & Negative & 10th & 100 & Context & Cultural & Single \\
\hline Chianese et al. (2016) & Both & Twitter & $\begin{array}{l}\text { Naples, Bari, Venice \& } \\
\text { Rome, Italy* }\end{array}$ & $\begin{array}{l}\text { Heritage-property-related } \\
\text { public event }\end{array}$ & Neutral & Dec 2014 - May 2015 & 400 & Content \& Context & Cultural & Multiple \\
\hline Claster et al. (2010) & Activated & Twitter & $\begin{array}{l}\text { Bangkok \& Phuket, } \\
\text { Thailand }\end{array}$ & Red Shirt Demonstration & Negative & Nov 2009 - May 2010 & $71 \mathrm{M}$ & Context & Cultural & Dual \\
\hline Fukui & tivat & Twitt & Iwate, Japan* & Earthquake and Tsunami & ive & & & & $\mathrm{Cl}$ & Single \\
\hline al. (2014) & Activat & Twitter \& Foursquare & Barcelona, Spain* & Congress 2012 & Positive & 2012 & $183 \mathrm{k}$ & Conten & Cultural & Single \\
\hline Monteiro et al. (2014) & Activated & Twitter & The Globe* & $\begin{array}{l}\text { Cases including possible del- } \\
\text { isting of Tasmanian Wilder- } \\
\text { ness from World Heritage }\end{array}$ & Negative & Dec 2013 - Jan 2014 & $12 \mathrm{k}$ & Content \& Context & $\begin{array}{l}\text { Cultural/ } \\
\text { Natural }\end{array}$ & Multiple \\
\hline Park et al. (2019) & Activate & ebc & & Landfall of $\mathrm{Hu}$ & Negative & Aug-Sep 2017 & $3 \mathrm{k}$ & & & Single \\
\hline $\begin{array}{l}\text { Taecharungroj and } \\
\text { Mathayomchan } \\
\text { (2019) }\end{array}$ & Both & TripAdvisor & Phuket, Thailand & Wave-hit on tour boat & Negative & & - & Content \& Context & $\begin{array}{l}\text { Cultural/ } \\
\text { Natural }\end{array}$ & Single \\
\hline Vassakis et al. (2019) & Both & $\begin{array}{l}\text { Instagram, Facebook, } \\
\text { Foursquare, \& Twitter }\end{array}$ & $\begin{array}{l}\text { Heraklion \& Chania, } \\
\text { Greece }\end{array}$ & $\begin{array}{l}\text { Video shooting of a popular } \\
\text { singer }\end{array}$ & Positive & Nov - Dec 2017 & - & Content \& Context & Cultural & Multiple \\
\hline Williams et al. (2017) & Activated & Twitter & Bournemouth, UK & Bournemouth Air Festival & Positive & $2011-2015$ & - & Structure \& Context & Cultural & Single \\
\hline
\end{tabular}

*The case study contains at least one UNESCO World Heritage property.

Table 1. A brief overview of the investigated publications in the systematic literature review classified as either "activated" or "both".

ical tests. The selection and screening of the literature is presented with PRISMA (Preferred Reporting Items for Systematic reviews and Meta-Analysis) standard (Boland et al., 2017; Liberati et al., 2009; Moher et al., 2009), as shown in Figure 5.

During full-text reading, the 73 included publications were classified as "everyday", "activated", or "both", corresponding with the scenarios defined in Section 2. Specifically, if one study explicitly declared an event as main focus for the case study, for example an international exposition, a natural disaster, and/or the crisis reaction for destination, it was labelled with "activated"; otherwise, if a study focused on the ordinary status of the case, it was labelled with "everyday"; for the special cases where both scenarios were emphasized and compared explicitly, they were labelled as "both". Moreover, messages about the social media platform, type, quantity and duration of data collection, case study, the discussed events and their polarity towards heritage were also recorded for each reviewed publication, not judging from any political standpoint.

\subsection{Main Findings}

Among the 73 included publications, 9 were about "activated" scenario while 59 were about "baseline" scenario, and only 5 were about both. The majority of publications mainly discussed the use of social media for heritage planning without mentioning any special events. The trend of such distinctions could be seen in Figure 6. In the past decade, though the research about normal everyday scenario has kept growing, especially after 2016, studies explicitly about the activated scenario dealing with event-related heritage management issues remained scarce, let alone studies combining and comparing the two.

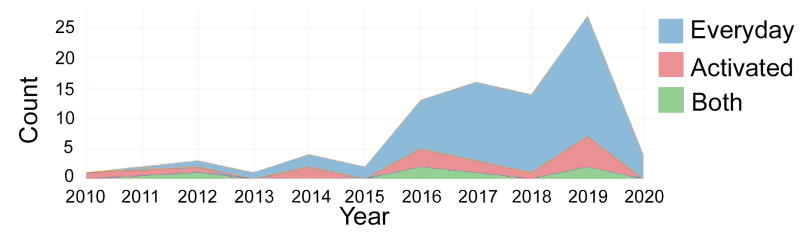

Figure 6. The number of publications with label of "everyday", "activated", and "both" each year from 2010 to 2020.

A summary of the publications with the label of either "activated" or "both" could be seen in Table 1. Like the example of fire and flood as radical events shown in Section 1, a plenty of activation came as consequences of natural disasters (Fukui and Ohe, 2019; Park et al., 2019; Taecharungroj and Mathayomchan, 2019). However, activated public engagement on social media could also happen after political events (Chaabani et al., 2018; Claster et al., 2010; Monteiro et al., 2014), largescale cultural activities (Amato et al., 2016; Gabrielli et al., 2014; Vassakis et al., 2019; Williams et al., 2017), or even general daily events (Battiato et al., 2016; Campillo-Alhama and Martinez-Sala, 2019; Chianese et al., 2016; Barbagallo et al., 2012), therefore not necessarily negative, nor radical. Among the studies, the majority focused on the regional- or nationallevel voices from either local residents and/or tourists as concerned community, while Monteiro et al. (2014) brought together the discussion about events such as the possible delisting of a UNESCO World Heritage property in Australia into the global context, showing the local and global sensitivities regarding World Heritage based on the spatiotemporal evolution of related tweets. Researchers mainly used the content-based information (e.g., words, pictures), network structure (e.g., user interaction, connectivity, temporal dynamics) and contextual aspects (e.g., geo-location) from the social media platforms to draw their conclusions in activated scenarios (Aggarwal, 2011), mainly from Twitter due to its timeliness and low time lag for updates (Williams et al., 2017). Natural language processing tools such as sentiment analysis and topic models were applied to mine the public opinions of heritage properties triggered by events (Gabrielli et al., 2014; Taecharungroj and Mathayomchan, 2019; Monteiro et al., 2014; Fukui and Ohe, 2019; Claster et al., 2010; Chaabani et al., 2018), and graphs/networks were constructed to find out the community structures (Williams et al., 2017; Barbagallo et al., 2012), critical influencers (Barbagallo et al., 2012; Campillo-Alhama and Martinez-Sala, 2019), popular destinations (Gabrielli et al., 2014), and to make personalized recommendations (Amato et al., 2016; Battiato et al., 2016). However, none of the presented studies in Table 1 have applied or developed heritage-specific tools targeted at revealing cultural significance, i.e., values and attributes of heritage properties, which should become an important initial step for the proposed framework (Bai et al., 2021).

Furthermore, Figure 7 shows information about data collection for all the included publications, which contained the collection period, duration, as well as the total size of collected data, when related information has been explicitly provided by the authors. It reveals that for the investigated studies within both scenarios, the data collection duration varied significantly, ranging from 3 weeks (Gabrielli et al., 2014) to 12 years (Ginzarly et al., 2019; Barros et al., 2020; Junker et al., 2017). Moreover, a shorter 

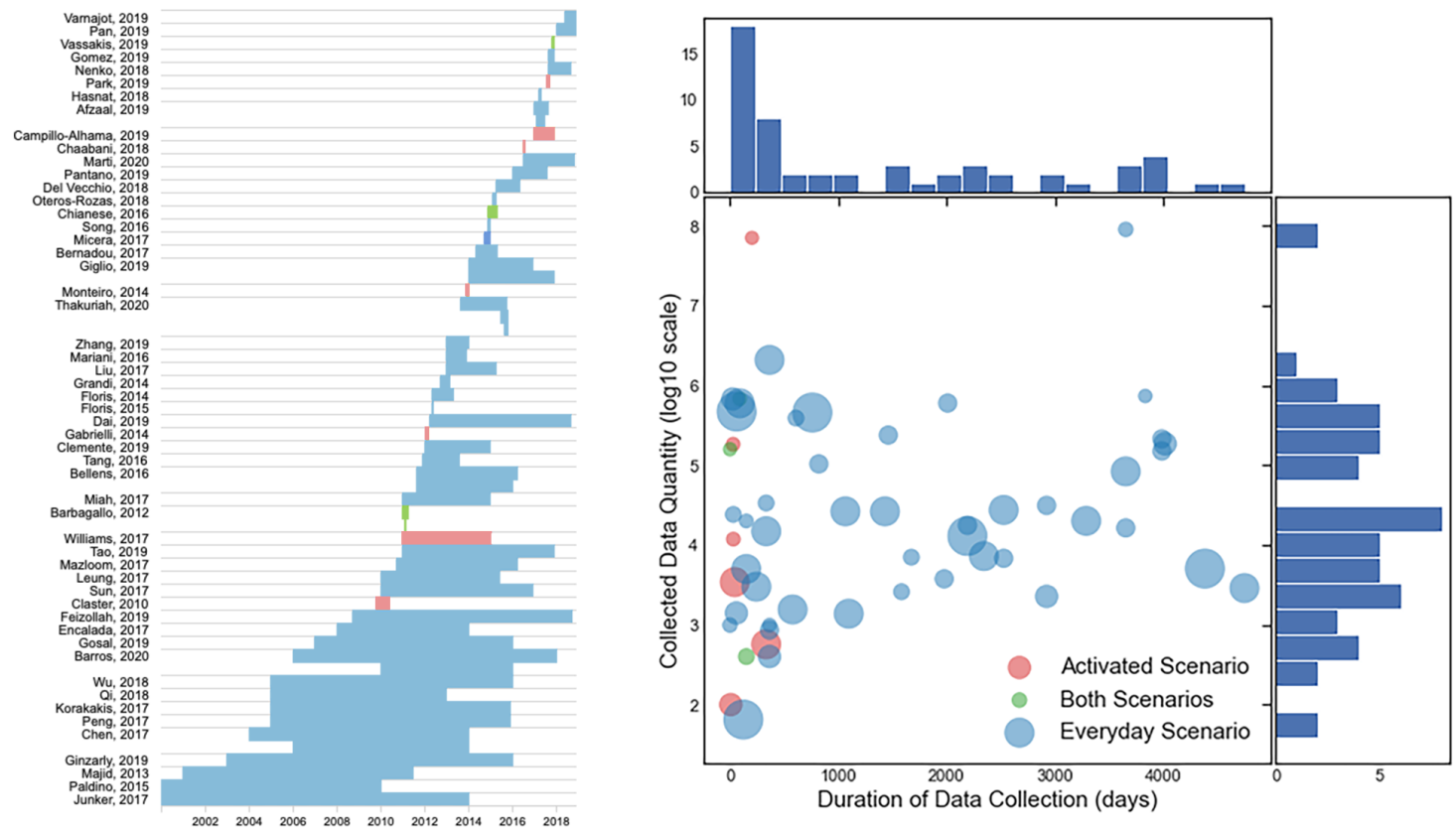

Figure 7. Left: the data collection duration (start time - end time) of the reviewed research; Right: the relationship between data collection duration and data quantity. The sizes of points show the proximity of the research to now, meaning that the later the record

is published, the larger the point. The distributions of the duration and quantity are shown with histograms, in top and right,

respectively. The colors in both graphs distinguish literature focused on "everyday", "activated" or "both" scenarios.

collection duration does not necessarily mean a smaller data quantity. Meanwhile, as the popularity of big data has been growing in the past decade, not all recent studies are processing a "bigger data" than before. Remarkably, the two studies with the largest data in the scale of $10^{8}$ were both conducted more than 5 years ago (Claster et al., 2010; Paldino et al., 2015). Furthermore, statistical $T$-tests showed that the studies focusing on the activated scenarios have a significantly shorter data collection duration than the studies merely focusing on everyday scenarios $(t=-3.22, p<0.01)$, while there is no significant difference found with the data quantity for different scenarios $(t=1.50, p=0.14)$. This again suggests that specific tools and algorithms to handle the large datasets on social media to obtain potentially useful information for heritage practitioners and researchers are urgently needed.

\section{CONCLUSIONS}

This paper presented a theoretical framework of distinguishing the social interaction of global online public for heritage properties as "everyday/baseline" and "activated/event-triggered" scenarios, both of which could contribute significantly to understand general public opinions and emotions, bridge official discourse from scholars and practitioners, and facilitate future planning actions. Evidences from Google Trend search engine, social media platforms, and current heritage literature has been presented to contextualize and validate the theoretical framework. It addressed the main theoretical and methodological approach of an ongoing research about social inclusion in heritage planning and management. However, further studies are needed to develop heritage-specific tools to deal with largescale data from social media, to construct proper networks for the both scenarios to capture useful information of the opinions and emotions of the online communities, to apply case studies in global context to validate the generalizability of the methods, and to link back to real-world heritage management and planning actions to facilitate decision-making processes. Empirical and theoretical investigations are further needed to understand the structure and dynamic in the constructed networks, and how such network structure and dynamic can help in formulating policies and actions in support of social inclusion in heritage planning. Once successfully employed, this research framework could benefit multiple stakeholders, including local heritage managers (e.g., municipalities, site directors), global organizations (e.g., UNESCO, ICOMOS, IUCN), general public (e.g., tourists, locals, global citizens), heritage experts and researchers, etc., all of which should be considered as concerned communities, contributing to inclusive heritage planning, going beyond cultural differences and geographical boundaries.

\section{ACKNOWLEDGEMENTS}

The presented study is within the framework of the HerilandConsortium. HERILAND is funded by the European Union's Horizon 2020 research and innovation programme under the Marie Sklodowska-Curie grant agreement No 813883.

\section{References}

Adamic, L. A., Lento, T. M., Adar, E., Ng, P. C., 2016. Information evolution in social networks. WSDM 2016 - Proceedings of the 9th ACM International Conference on Web Search and Data Mining, 473-482.

Adams, R. P., MacKay, D. J., 2007. Bayesian online changepoint detection. arXiv preprint arXiv:0710.3742.

Aggarwal, C. C., 2011. An Introduction to Social Network Data Analytics. C. C. Aggarwal (ed.), Social Network Data Analytics, SPRINGER, chapter 1,1-15. 
Amato, F., Cozzolino, G., Di Martino, S., Mazzeo, A., Moscato, V., Picariello, A., Romano, S., Sperlí, G., 2016. Opinions analysis in social networks for cultural heritage applications. Smart Innovation, Systems and Technologies, 55, 577 586. https://www.scopus.com/inward/record.uri?eid=2-s2.084977080546doi $=10.1007$

Australia ICOMOS, 2013. The Burra Charter: The Australia ICOMOS Charter for Places of Cultural Significance (1999). Technical report.

Bai, N., Luo, R., Nourian, P., Roders, A. P., 2021. WHOSe Heritage: Classification of UNESCO World Heritage "Outstanding Universal Value" Documents with Smoothed Labels. arXiv preprint arXiv:2104.05547.

Bandarin, F., Van Oers, R., 2012. The historic urban landscape: managing heritage in an urban century. John Wiley \& Sons.

Barbagallo, D., Bruni, L., Francalanci, C., Giacomazzi, P., 2012. An Empirical Study on the Relationship between Twitter Sentiment and Influence in the Tourism Domain. L. Fuchs, $\mathrm{M}$ and Ricci, $\mathrm{F}$ and Cantoni (ed.), INFORMATION AND COMMUNICATION TECHNOLOGIES IN TOURISM 2012, SPRINGER-VERLAG WIEN, SACHSENPLATZ 4-6, A-1201 VIENNA, AUSTRIA, 506-516.

Barros, C., Moya-Gómez, B., Gutiérrez, J., 2020. Using geotagged photographs and GPS tracks from social networks to analyse visitor behaviour in national parks. Current Issues in Tourism, 23(10), 1291-1310.

Battiato, S., Farinella, G. M., Milotta, F. L., Ortis, A., Addesso, L., Casella, A., D'Amico, V., Torrisi, G., 2016. The social picture. ICMR 2016 - Proceedings of the 2016 ACM International Conference on Multimedia Retrieval, 397-400.

Boland, A., Cherry, M. G., Dickson, R., 2017. Doing a Systematic Review: A Student's Guide. SAGE PUBLICATIONS INC.

Bond, R., Messing, S., 2015. Quantifying Social Media's Political Space: Estimating Ideology from Publicly Revealed Preferences on Facebook. American Political Science Review, 109(1), 62-78.

Bruns, A., Burgess, J. E., Crawford, K., Shaw, F., 2012. \# qldfloods and QPSMedia: Crisis Communication on Twitter in the 2011 South East Queensland Floods. http://cci.edu.au/floodsreport.pdf.

Calder, M., Craig, C., Culley, D., de Cani, R., Donnelly, C. A., Douglas, R., Edmonds, B., Gascoigne, J., Gilbert, N., Hargrove, C., Hinds, D., Lane, D. C., Mitchell, D., Pavey, G., Robertson, D., Rosewell, B., Sherwin, S., Walport, M., Wilson, A., 2018. Computational modelling for decisionmaking: Where, why, what, who and how. Royal Society Open Science, 5(6).

Campillo-Alhama, C., Martinez-Sala, A.-M., 2019. Events 2.0 in the transmedia branding strategy of World Cultural Heritage Sites. PROFESIONAL DE LA INFORMACION, 28(5).

Chaabani, Y., Toujani, R., Akaichi, J., 2018. Sentiment analysis method for tracking touristics reviews in social media network. Smart Innovation, Systems and Technologies, 76, 299-310. https://www.scopus.com/inward/record.uri?eid=2s2.0-85020455910doi $=10.1007$
Cheng, J., Adamic, L. A., Kleinberg, J., Leskovec, J., 2016. Do cascades recur? 25th International World Wide Web Conference, WWW 2016, 671-681.

Chianese, A., Marulli, F., Piccialli, F., 2016. Cultural Heritage and Social Pulse: A Semantic Approach for CH Sensitivity Discovery in Social Media Data. Proceedings - 2016 IEEE 10th International Conference on Semantic Computing, ICSC 2016, Institute of Electrical and Electronics Engineers Inc., 459-464.

Claster, W. B., Cooper, M., Sallis, P., 2010. Thailand - Tourism and conflict. Modeling sentiment from twitter tweets using naïve bayes and unsupervised artificial neural nets. School of Asia Pacific Management, Ritsumeikan Asia Pacific University, Beppu, Japan, 89-94.

Couclelis, H., 2005. "Where has the future gone?" Rethinking the role of integrated land-use models in spatial planning. Environment and Planning A, 37(8), 1353-1371.

Dong, W., Heller, K., Pentland, A. S., 2012. Modeling Infection with Multi-agent Dynamics.

Easley, D., Kleinberg, J., 2010. Networks, Crowds and Markets: Reasoning about a Highly Connected World. Cambridge University Press, Cambridge.

Fischer, G., 2009. Democratizing design: New challenges and opportunities for computer-supported collaborative learning. Computer Supported Collaborative Learning Practices, CSCL 2009 Conference Proceedings - 9th International Conference, 282-286.

Fukui, M., Ohe, Y., 2019. Assessing the role of social media in tourism recovery in tsunami-hit coastal areas in Tohoku, Japan. Tourism Economics. https://www.scopus.com/inward/record.uri?eid=2-s2.085061104613 doi $=10.1177$

Gabrielli, L., Rinzivillo, S., Ronzano, F., Villatoro, D., 2014. From Tweets to Semantic Trajectories: Mining Anomalous Urban Mobility Patterns. D. Nin, J and Villatoro (ed.), CITIZEN IN SENSOR NETWORKS, Lecture Notes in Artificial Intelligence, 8313, SPRINGER-VERLAG BERLIN, HEIDELBERGER PLATZ 3, D-14197 BERLIN, GERMANY, 26-35.

Ginzarly, M., Pereira Roders, A., Teller, J., 2019. Mapping historic urban landscape values through social media. Journal of Cultural Heritage, 36, 1-11. http://dx.doi.org/10.1016/j.culher.2018.10.002.

IUCN, ICOMOS, ICROM, WHC, 2010. Guidance on the preparation of retrospective Statements of Outstanding Universal Value for World Heritage Properties. Technical report.

Jansen, W. S., Otten, S., van der Zee, K. I., Jans, L., 2014. Inclusion: Conceptualization and measurement. European journal of social psychology, 44(4), 370-385.

Janssen, J., Luiten, E., Renes, H., Stegmeijer, E., 2017. Heritage as sector, factor and vector: conceptualizing the shifting relationship between heritage management and spatial planning. European Planning Studies, 25(9), 1654-1672. https://doi.org/10.1080/09654313.2017.1329410.

Jokilehto, J., 2006. World Heritage: Defining the Outstanding Universal Value. City \& Time, 2(2), 1-10. 
Jokilehto, J., 2008. What is OUV? Defining the Outstanding Universal Value of Cultural World Heritage Properties. Technical report, ICOMOS, ICOMOS Berlin.

Junker, C., Akbar, Z., Cuquet, M., 2017. The network structure of visited locations according to geotagged social media photos. $\operatorname{arXiv}, 1-8$.

Katz, L., 1953. A new status index derived from sociometric analysis. Psychometrika, 18(1), 39-43.

Lazer, D., Pentland, A., Adamic, L., Aral, S., Barabasi, A.-L., Brewer, D., Christakis, N., Contractor, N., Fowler, J., Gutmann, M. et al., 2009. Social science. Computational social science. Science (New York, NY), 323(5915), 721-723.

Liberati, A., Altman, D. G., Tetzlaff, J., Mulrow, C., Gøtzsche, P. C., Ioannidis, J. P., Clarke, M., Devereaux, P. J., Kleijnen, J., Moher, D., 2009. The PRISMA statement for reporting systematic reviews and meta-analyses of studies that evaluate health care interventions: explanation and elaboration. Journal of clinical epidemiology, 62(10), e1-e34.

Lipizzi, C., Iandoli, L., Marquez, J. E. R., 2015. Extracting and evaluating conversational patterns in social media: A sociosemantic analysis of customers' reactions to the launch of new products using Twitter streams. International Journal of Information Management, 35(4), 490-503.

Milgram, S., 1967. The small world problem. Psychology today, 2(1), 60-67.

Moher, D., Liberati, A., Tetzlaff, J., Altman, D. G., Grp, P., 2009. Preferred Reporting Items for Systematic Reviews and Meta-Analyses: The PRISMA Statement (Reprinted from Annals of Internal Medicine). Physical Therapy, 89(9), 873880.

Monteiro, V., Henriques, R., Painho, M., Vaz, E., 2014. Sensing World Heritage An Exploratory Study of Twitter as a Tool for Assessing Reputation. O. Murgante, B and Misra, S and Rocha, AMAC and Torre, $\mathrm{C}$ and Rocha, JG and Falcao, MI and Taniar, D and Apduhan, BO and Gervasi (ed.), COMPUTATIONAL SCIENCE AND ITS APPLICATIONS - ICCSA 2014, PT II, Lecture Notes in Computer Science, 8580, Univ Minho; Univ Perugia; Univ Basilicata; Monash Univ; Kyushu Sangyo Univ; Assoc Portuguesa Investigacao Operac, $404+$.

Munar, A. M., 2012. Social Media Strategies and Destination Management. SCANDINAVIAN JOURNAL OF HOSPITALITY AND TOURISM, 12(2), 101-120.

Olsson, K., 2008. Citizen input in urban heritage management and planning: A quantitative approach to citizen participation. Town Planning Review, 79(4), 371-395.

Paldino, S., Bojic, I., Sobolevsky, S., Ratti, C., González, M. C., 2015. Urban magnetism through the lens of geo-tagged photography. EPJ Data Science, 4(1), 117. https://www.scopus.com/inward/record.uri?eid=2-s2.084933512701 doi $=10.1140$

Park, D., Kim, W. G., Choi, S., 2019. Application of social media analytics in tourism crisis communication. Current Issues in Tourism, 22(15), 1810-1824.

Pentland, A., 2015. Social Physics: How social networks can make us smarter. Penguin.
Pereira Roders, A., 2019. The Historic Urban Landscape Approach in Action: Eight Years Later. Reshaping Urban Conservation, 21-54.

Rochon, T. R., 1998. Culture moves: Ideas, activism, and changing values. Princeton University Press.

Roders, A. P., Van Oers, R., 2011. World Heritage cities management. Facilities, 29(7/8), 276-285.

Schroeder, A., Pennington-Gray, L., Donohoe, H., Kiousis, S., 2013. Using Social Media in Times of Crisis. Journal of Travel and Tourism Marketing, 30(1-2), 126-143.

Taecharungroj, V., Mathayomchan, B., 2019. Analysing TripAdvisor reviews of tourist attractions in Phuket, Thailand. Tourism Management, 75(July), 550-568.

Tarrafa Silva, A., Pereira Roders, A., 2010. The cultural significance of World Heritage cities : Portugal as case study. Heritage and Sustainable Development, Évora, Portugal.

Taylor, J., Gibson, L. K., 2017. Digitisation, digital interaction and social media: embedded barriers to democratic heritage. International Journal of Heritage Studies, 23(5), 408-420.

UNESCO, 1972. Convention Concerning the Protection of the World Cultural and Natural Heritage. Technical Report november, UNESCO, Paris.

UNESCO, 2008. Operational guidelines for the implementation of the world heritage convention. Technical Report July, UNESCO World Heritage Centre.

UNESCO, 2011. RECOMMENDATION ON THE HISTORIC URBAN LANDSCAPE. Technical report, UNESCO, Paris.

van Dijck, J., 2011. Flickr and the culture of connectivity: Sharing views, experiences, memories. MEMORY STUDIES, 4(4), 401-415.

Vassakis, K., Petrakis, E., Kopanakis, I., Makridis, J., Mastorakis, G., 2019. Location-based social network data for tourism destinations. Springer Singapore.

Wasserman, S., Faust, K., 1994. Social Network Analysis: Methods and Applications. Cambridge University Press.

Waterton, E., Smith, L., Campbell, G., 2006. The utility of discourse analysis to heritage studies: The Burra Charter and social inclusion. International journal of heritage studies, 12(4), 339-355.

Watts, D. J., Strogatz, S. H., 1998. Collective dynamics of 'small-world'networks. nature, 393(6684), 440-442.

Williams, N. L., Inversini, A., Ferdinand, N., Buhalis, D., 2017. Destination eWOM: A macro and meso network approach? Annals of Tourism Research, 64, 87101. https://www.scopus.com/inward/record.uri?eid=2-s2.085015696520 doi $=10.1016$

Zhai, X., Luo, Q., Wang, L., 2020. Why tourists engage in online collective actions in times of crisis: Exploring the role of group relative deprivation. Journal of Destination Marketing and Management, 16(August 2019). 